\title{
A empregabilidade no setor contábil e a questão de gênero em Santa Catarina
}

\begin{abstract}
Mariana Küster *
Debora Aparecida Almeida**

\section{Resumo}

Conhecer o atual mercado de trabalho se faz necessário, seja pelos desafios profissionais ou pelas oportunidades de mercado. Analisando o atual cenário econômico, nota-se que vários setores sofrem com a alta rotatividade de pessoal, seja pelo corte de despesas, seja pela demanda inferior de serviço ou ainda por outras diversas variáveis. O objetivo geral da pesquisa concentrou-se em analisar a demanda de profissionais contábeis em Santa Catarina relacionando-a com a rotatividade e com a questão de gênero. A pesquisa configura-se como um estudo de cunho quantitativo, pautado em uma metodologia descritiva desenvolvida por meio de procedimento documental com dados do Cadastro Geral de Empregados e Desempregados (CAGED) permeado por informações sobre cargos, salários, unidade da federação, sexo e faixa etária. Os meses selecionados foram de janeiro a junho de 2018. Dentre as principais conclusões citam-se: índices equilibrados de profissionais admitidos e desligados, maior percentual de mulheres contratadas e as regiões Norte e Vale do Itajaí consideradas de maior concentração de profissionais contábeis em Santa Catarina.
\end{abstract}

Palavras-Chave: centralização; empregabilidade; gênero; mercado de trabalho.

\section{Employability in the accounting sector and the gender issue in Santa}

\section{Catarina}

\begin{abstract}
To understand the current job market is a necessary information, either for professional challenges or market opportunities. Analyzing the current economic scenario it can be observed that many sectors suffer from the high turnover of staff, either by cutting expenses or lower demand of service and also by other variables. The general objective of this research is analyzing the demand for accounting professionals in Santa Catarina and consider the turnover of professionals in the area, relating it to the mobility and gender issues. The research has a quantitative nature based on a descriptive methodology developed through the documental procedure with data from CAGED (General Register of Employed and Unemployed) permeated by information about positions, wages, Federative Unit (state), gender and age range. The selected months were from January, to July of 2018. Among the mais conclusions we can mention: balanced índice of admitted and dismissed professionals, higher percentage of hired women and the North and Vale do Itajaí regions considered to have the highest concentration of accounting professionals in Santa Catarina
\end{abstract}

Keywords: centralization; employability; gender. job market.

JEL: J20, J21, J23, J160.

\footnotetext{
*Bacharel em Ciências Contábeis pela Universidade do Contestado (UnC), Campus Curitibanos. Email: mariana_kuster97@outlook.com

** Professora do Núcleo de Ciências Sociais Aplicadas da Universidade do Contestado (Um), Campus Curitibanos. E-mail: deboraalmeida@unc.br
} 


\section{Introdução}

Conhecer o atual mercado de trabalho se faz necessário, seja pelos desafios profissionais, seja pelas oportunidades de mercado. Analisando o atual cenário econômico nota-se que vários setores sofrem com a alta rotatividade de pessoal, com o corte de despesas, com a demanda inferior de serviço ou ainda por outras diversas variáveis.

Segundo dados coletados pelo IBGE, o índice de desocupação no Brasil com relação ao segundo bimestre de 2018 é de 12,40\%, evidenciando uma queda da taxa de desemprego de $0,7 \%$ em relação ao primeiro bimestre do ano. Com os dados recentes de desemprego, cabe analisar como o setor contábil se encontra no mercado de trabalho atual.

É fundamental também analisar a diferença de gênero no ramo contábil, já que sabemos que ainda há uma desigualdade significativa nos dias atuais. Segundo Brighenti, Jacomossi e Silva (2015), um estudo feito pelo IBGE em 2012 constatou que as mulheres representam 46,1\% da população economicamente ativa no Brasil e, 53,7\% da população em idade ativa.

A problemática em questão visa estabelecer uma avaliação acerca da rotatividade dos profissionais contábeis no estado de Santa Catarina, no primeiro semestre de 2018. Qual a relação entre rotatividade e a área técnica de atuação? Como se dá a configuração entre gênero e especialidade?

O objetivo geral da pesquisa concentrou-se em analisar a demanda de profissionais contábeis em Santa Catarina relacionando-a com a rotatividade e com a questão de gênero. Os objetivos específicos foram: verificar a quantidade de profissionais contábeis registrados em Santa Catarina; identificar onde estão centralizados os profissionais contábeis bem como, suas especialidades; e, comparar o índice de homens e mulheres registrados na profissão contábil em período recente.

Em outros termos, espera-se com este artigo, conhecer como o setor contábil se encontra em Santa Catarina e quais profissionais tem maior demanda no mercado de trabalho e quais tem maiores oportunidades; e diferenciando-os por gêneros para constatar se há diferenças neste setor.

Para tanto, o artigo encontra-se dividido em seis seções. Nesta primeira seção, traçase o objetivo principal; na segunda seção, discutem-se a rotatividade e os seus desafios; na terceira seção, apontam-se as questões de gênero na área da contabilidade; na $4^{\mathrm{a}}$. seção 
descreve-se a metodologia; na quinta seção apresentam-se os resultados e as discussões; e, por fim, na sexta seção faz-se as considerações finais.

\section{A rotatividade e seus desafios}

Com o avanço da globalização, o mercado de trabalho vem ficando cada vez mais competitivo e as empresas vem buscando sempre maior qualificação de seus colaboradores. Com o mercado de trabalho altamente competitivo, é grande a busca por um profissional qualificado e ideal para o cargo, pois, admitir um candidato com perfil inadequado para o serviço pode causar prejuízos aos negócios. Por outro lado, perder um colaborador é sempre prejudicial para a empresa, em especial quando se trata de bons funcionários (SEBRAE, 2016).

Visto que a rotatividade, admissão e demissão de funcionários sucessivamente é grande, observa- se que diversos fatores influenciam, desde a falta de qualificação até a falta de valorização. Por sua vez, as empresas buscam dirimir esses custos de sua empresa. No ramo contábil, o turnover $^{l}$ pode existir por vários motivos: ou pela demanda de serviços, pela crise financeira ou ainda, pela qualificação de profissionais competitivos.

No contexto brasileiro, o que se observa é que as empresas enfrentam cada vez mais dificuldades em manter seus funcionários. Apesar de a última década ter sido marcada por algum crescimento da economia e da grande oferta de empregos, ambos favorecidos pela estabilização do processo inflacionário, o período também se caracterizou por uma redução do tempo de duração dos vínculos trabalhistas. (FERREIRA; ALMEIDA, 2015). Em verdade, as empresas buscam maior qualificação de seus colaboradores, porém, isso faz com que haja concorrência entre as empresas, e faça o funcionário ficar mais valorizado perante o mercado de trabalho.

Em consequência disso, no setor contábil, por exemplo, as normas técnicas e leis trabalhistas estão em oscilação constantemente $O$ profissional que se adequa a essas mudanças e busca aperfeiçoamento, se torna mais valorizado no mercado de trabalho.

Segundo Rodriges, Polizzi e Siqueira (2015), as pessoas que constituem uma organização são uma fonte valiosa de vantagem competitiva, se a empresa souber aproveitar e desenvolver as qualidades e os conhecimentos específicos desses indivíduos, ela obterá

${ }^{1} O$ turnover é a alta rotatividade de funcionários em uma empresa, ou seja, um empregado é admitido e outro desligado de maneira sucessiva. 
eficácia nos produtos e serviços, e, consequentemente, um diferencial competitivo em relação aos concorrentes.

Do mesmo modo, as causas dos desligamentos das empresas podem ser diversas, por exemplo: os indivíduos podem solicitar sua demissão da empresa por descontentamento com alguma política da empresa, falta de motivação, ou busca de uma melhor colocação profissional. Por outro lado, a empresa também se coloca no direito de buscar profissionais mais capacitados para integrar o seu quadro funcional ou ainda procurar pela inovação e reforma profissional de seus colaboradores (MEDEIROS; ALVES; RIBEIRO, 2012, p. 118; apud PINHEIRO; SOUZA, 2013, p. 4). Certamente, a rotatividade está presente dos dois lados, tanto pela empresa como pelo funcionário, porém, cabe a empresa na hora da seleção, escolher o melhor colaborador para cada cargo.

Além das despesas, com recrutamento, seleção e treinamento de novos empregados, pode-se destacar ainda a perda de conhecimentos explícitos e táticos essenciais, construídos ao longo do tempo, por meio de mecanismos socialmente complexos. (BARNEY; WRIGHT; 1998; apud OLIVEIRA; ROCHA, 2017, p.420). Por certo que, a empresa é a que mais sai perdendo com a rotatividade de funcionários, não só pelos custos da própria demissão, mas um funcionário que está há tempos na empresa se torna mais lucrativo. Todavia, nos dias atuais manter um funcionário por muito tempo é uma tarefa difícil, pois suas experiências o tornam valorizado no mercado.

\section{Questões de gênero no setor contábil}

A desigualdade de gênero ainda é um problema global, apesar das mulheres terem adquirido um grande avanço nas últimas décadas, esse processo de igualdade ainda é muito lento e imprevisível. Conforme Araújo e Ribeiro (2001 p. 2; apud BRIGHENTI; JACOMOSSI; SILVA 2015, p. 111) a discriminação diz respeito “à situação onde indivíduos igualmente produtivos são diferentemente avaliados com base em atributos não produtivos".

A conquista da autonomia é um importante passo para a redução das desigualdades de gênero, que estão presentes em diferentes dimensões da sociedade brasileira. Autonomia se refere ao exercício, pelas mulheres, do poder de decisão sobre suas vidas e corpos, o que implica o rompimento das históricas relações de subordinação, exploração e dependência 
que constrangem suas vidas no plano pessoal, econômico, político e social (NASCIMENTO, 2014).

Em síntese, por muito tempo as mulheres foram tratadas de forma desigual com relação aos aspectos citados, nos dias atuais houve uma considerável mudança com relação à desigualdade gênero. Contudo, ainda existem muitas diferenças, pois mesmo as mulheres estudando e se aprimorando mais que os homens, no modo geral a diferença salarial é evidente.

A independência feminina é justificada pela busca continua de autonomia para ampliar a participação da mulher nos diferentes setores da sociedade, economia, ciência e política. Dessa forma, o empoderamento feminino amplia significativamente a partir dos avanços dos sistemas políticos e democráticos, no acesso aos direitos humanos e na participação da mulher na sociedade (BAQUERO, 2012; apud OLIVEIRA et al., 2015). A crescente autonomia feminina nos últimos anos mostra como a mulher vem ganhando participação em diferentes setores na sociedade, de forma progressivamente vem buscando qualificação.

Como descrito por Nascimento e Alves (2014), a história da mulher na contabilidade é recente, em décadas passadas, o ingresso em uma faculdade, no curso de Ciências Contábeis era marcado pela presença masculina. A mulher vem aumentando seu ingresso na contabilidade lentamente, mostrando que é tão capaz quanto o homem na elaboração, análise e interpretação das demonstrações contábeis.

Dessa forma, a mulher contabilista tem conquistado seu reconhecimento no mercado de trabalho. Sua representatividade aumenta constantemente, demonstrando sua importância na profissão contábil. Se analisarmos a História, é possível visualizar o caminho traçado pelas mulheres, que, gradativamente, ultrapassam obstáculos e vem conquistando seu espaço no mercado de trabalho em todos os setores (MOTA; SOUZA, 2013; apud BRIGHENTI; JACOMOSSI; ZANIEVICZ, 2015, p.113). Certamente, o empoderamento feminino amplia significativamente com o passar dos anos; de forma crescente, as mulheres se fazem presente em diversos setores da sociedade de forma autônoma e ativa, aprimorando gradativamente a igualdade de gênero.

Apesar da superioridade escolar feminina, expressa pela população adulta feminina ter maior nível de instrução que a masculina, os resultados no mercado de trabalho não favorecem as mulheres. As mulheres que vivem nos municípios da Região Sul, por outro lado, apresentam as taxas de atividade mais elevadas dentre as regiões brasileiras $(60,8 \%)$, que estão presentes principalmente nas áreas leste e oeste do Estado de Santa Catarina 
(IBGE, 2018). É evidente as mulheres estão se especializando cada vez mais, para conquistar de forma mais abrangente o mercado de trabalho, porém ainda há desigualdades de gênero, seja em oportunidades, seja em questões salariais.

Em conformidade com o Conselho Federal de Contabilidade (CFC/SC, 2017), as contadoras, apesar de representarem quase metade dos profissionais de Contabilidade, enfrentam o mesmo problema que a maioria das mulheres no mundo corporativo depara. As diferenças salariais comparativamente aos homens, ainda são significativas (BRIGHENTI; JACOMOSSI; ZANIEVICZ, 2015).

Mesmo que de modo geral estejam mais preparadas, as mulheres ainda sentem dificuldades com as questões salariais se comparadas ao homem. Ainda existem barreiras invisíveis que a mulher deve opor-se, pois a desigualdade de gênero infelizmente está enraizada na nossa sociedade. Como exemplo, na sociedade atual, homens e mulheres que tem a mesma formação e cargo no trabalho, possuem diferenças salariais, no poder da autonomia empresarial e em todos os setores da sociedade.

\section{Materiais e métodos}

A pesquisa configura-se como um estudo de cunho quantitativo pautado em uma metodologia descritiva, desenvolvida por meio de procedimento documental com dados atuais do Cadastro Geral de Empregados e Desempregados (CAGED) (BRASIL. MTE, 2018) permeado por informações sobre cargos, salários, unidade da federação, sexo e faixa etária. Os meses selecionados foram: janeiro, fevereiro, março, abril, maio e junho de 2018.

Os dados permitiram analisar a quantidade de profissionais contábeis localizados em Santa Catarina e onde estão mais centralizados. E isso, possibilitou realizar análise estatística e demonstração gráfica dos resultados, com informações por nível regional, cargos e gêneros. Dentre os pontos principais, permitiram-se destacar a relação de profissionais contábeis em Santa Catarina, quais Classificação Brasileira de Ocupações (CBO’s) tem maior presença no Estado e, também, a diferença entre homens e mulheres na área contábil.

\section{Resultados e discussões}

Abaixo, segue a análise dos resultados em observância a coleta de dados ora efetuada. Em relação ao gênero de profissionais efetivados no ramo contábil em Santa Catarina o 
percentual de homens é $30 \%$ e mulheres de $70 \%$ num total de 6.451 profissionais analisados no primeiro semestre de 2018. O que mostra que há uma grande desigualdade entre os sexos, evidenciando que a mulher ganhou um vasto espaço no mercado de trabalho na área contábil, devido a maiores índices de graduação ou até mesmo, por merecimento e qualificação.

Gráfico 1 - Profissionais efetivados no ramo contábil por sexo em Santa Catarina, $1^{\circ}$. semestre de 2018

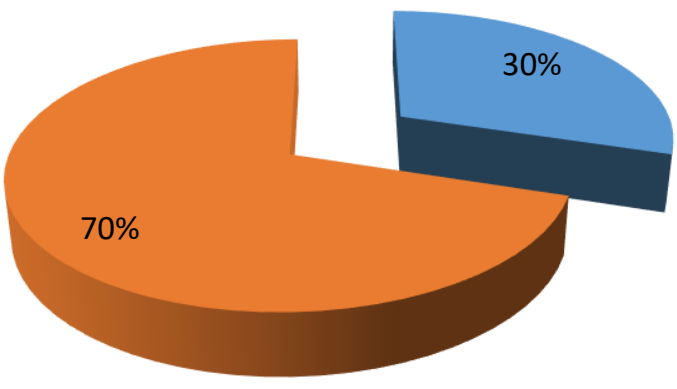

- MASCULINO

FEMININO

Fonte: Elaborado a partir do CAGED - BRASIL, MTE (2018).

Segundo pesquisas de Machado e Granemann (2017), através dos microdados do CAGED, o estudo revelou que as mulheres estão no mercado contábil com mais instrução que o homem, porém seus ganhos foram $36 \%$ mais baixos que dos homens dentro das empresas que atuam, revelando uma disparidade nas contratações entre os gêneros aqui estudados.

Gráfico 2 - Auditores admitidos e desligados em Santa Catarina, $1^{\circ}$. semestre de 2018
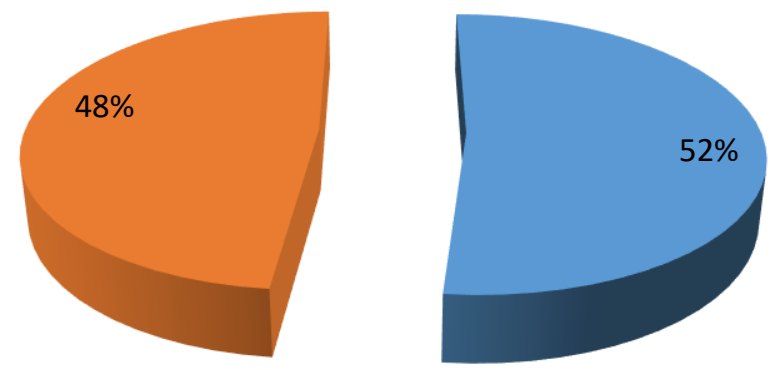

- ADMITIDO

DESLIGADO

Fonte: Fonte: Elaborado a partir do CAGED - BRASIL, MTE (2018). 
Em relação aos auditores admitidos e desligados, pode-se notar que o percentual não tem muita variação. Totalizando uma movimentação de 153 auditores entre admissões e desligamentos em todo território catarinense, observa-se que o índice de admissões foi pouco superior ao de demissões, conforme demonstra o gráfico.

Notou-se também que os auditores apresentaram a seguinte distribuição: (71) 48\% homens; e, (82) 52\% mulheres. Tais números evidenciaram o empoderamento feminino na profissão de auditor contábil no Estado de Santa Catarina.

Gráfico 3 - Contadores admitidos e desligados em Santa Catarina, $1^{\circ}$. semestre de 2018
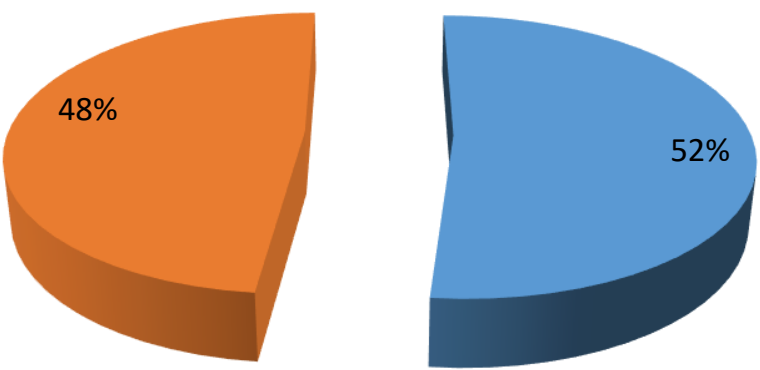

ADMITIDO

DESLIGADO

Fonte: Fonte: Elaborado a partir do CAGED - BRASIL, MTE (2018).

Os contadores, assim como os auditores, mantiveram a média de contração e demissão do período analisado. Podendo, assim, dizer que existe rotatividade nesse cargo, pois, as demissões e desligamentos permaneceram com índices equilibrados.

Gráfico 4 - Peritos admitidos e desligados em Santa Catarina, $1^{\circ}$. semestre de 2018
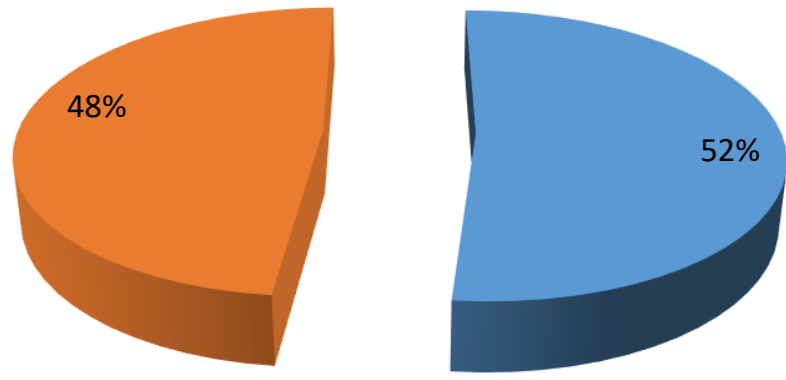

ADMITIDO

DESLIGADO

Fonte: Fonte: Elaborado a partir do CAGED - BRASIL, MTE (2018). 
Ressalta-se o registro de percentual muito pequeno de peritos em Santa Catarina, sendo apenas três peritos, conforme os dados apresentados no CAGED. Dados apontaram duas (2) mulheres e um (1) homem registrados em perícia contábil no Estado Catarinense.

Gráfico 5 - Auxiliar de contabilidade admitidos e desligados em Santa Catarina, $1^{\circ}$. semestre de 2018
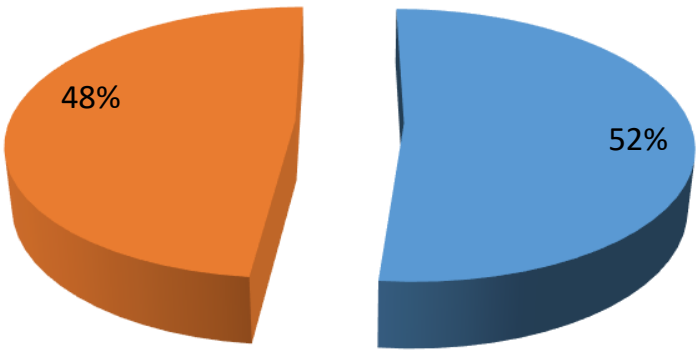

$\because$ ADMITIDO

DESLIGADO

Fonte: Fonte: Elaborado a partir do CAGED - BRASIL, MTE (2018).

O total de admissões e demissões de auxiliar contábil ficou estabilizado. Em Santa Catarina, havia 4.991 auxiliares contábeis. Considerando todos os CBO’s, não verificou variação acentuada de demissões e admissões, mesmo com o momento econômico do país, com muitas empresas em crise, mas os serviços contábeis mantêm sempre uma boa demanda. Apesar disso, os gráficos mostram que ocorreu muita rotatividade no ramo contábil, o que pode ser justificado por diversos fatores. Sabe-se que o turnover gera custos significativos para as empresas, no qual podem prejudicá-las futuramente. Assim, cabe cada gestor analisar as causas e efeitos desse fator para evitar problemas futuros.

Gráfico 6 - Total de admitidos por gênero em Santa Catarina. $1^{\circ}$. semestre de 2018

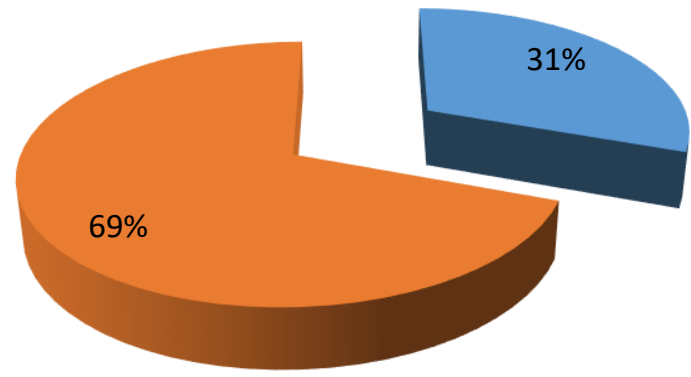

- HOMENS

MULHERES

Fonte: Fonte: Elaborado a partir do CAGED - BRASIL, MTE (2018). 
Dos profissionais admitidos em Santa Catarina 69\% eram mulheres e 31\% homens, mostrando uma diferença de gênero. Conforme dados do IBGE, a mulher vem se qualificando cada vez mais, motivo pelo qual, determina o aumento significativo nas contratações femininas, já que, as empresas sempre buscam maior qualificação profissional para seu quadro de colaboradores.

Gráfico 7 - Total de desligados por gênero em Santa Catarina, $1^{\circ}$. semestre de 2018

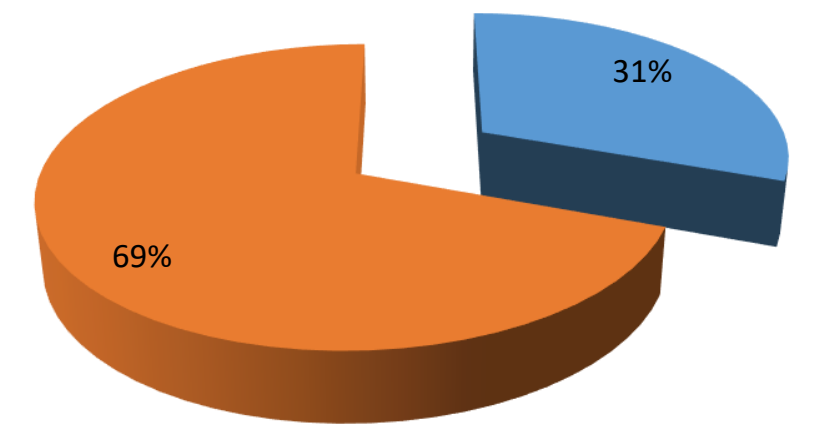

HOMENS

MULHERES

Fonte: Fonte: Elaborado a partir do CAGED - BRASIL, MTE (2018).

Cada vez mais, presenciamos figuras femininas ocupando cargos importantes, inclusive no mundo dos negócios, que antes eram majoritariamente ocupados por homens. De acordo com o Censo da Educação Superior, de 2015, os cursos da área de Ciências Sociais Aplicadas estão entre os preferidos das mulheres, sendo um deles as Ciências Contábeis. Eram mais de 209 mil mulheres matriculadas em Ciências Contábeis e cerca de 149 mil homens, em 2015 (PASETTO, 2018).

O índice de demissões converge com o índice de admissões acima citado, os profissionais demitidos também tiveram uma variação significativa de gênero, mostrando que a mulher tem um índice maior de demissões, que se justifica pelo fato de também estarem em maior número quando se trata de contratações.

Concluindo mais uma vez, que o setor contábil tem uma grande taxa de rotatividade, que como visto, pode se tornar prejudicial ás empresas. Os motivos dos desligamentos podem ser diversos. Conforme citado por Closer (2005) em relação à profissão contábil, Santos (2002, p. 7), afirma que "as perspectivas profissionais na área contábil são muito promissoras". Marion (1997, p.4), reitera que "novas perspectivas profissionais vão surgindo". 
Gráfico 8 - Distribuição de atividades por CBO na área contábil em Santa Catarina, $1^{\circ}$. semestre de 2018

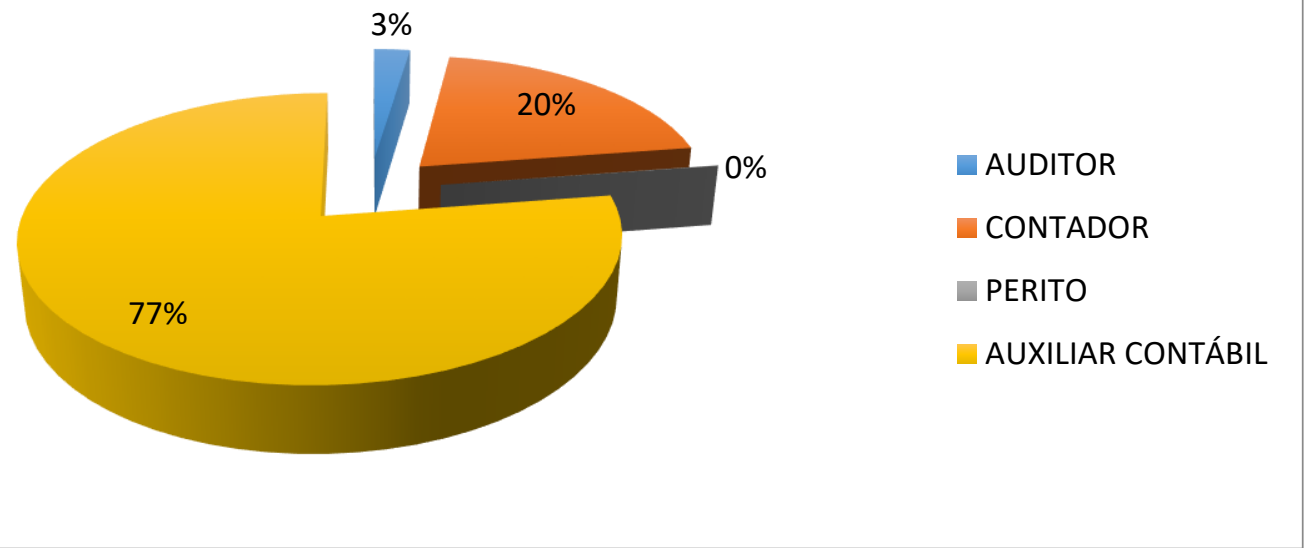

Fonte: Fonte: Elaborado a partir do CAGED - BRASIL, MTE (2018).

O que chama a atenção nas atividades contábeis é que há um número muito pequeno de auditores e peritos registrados em Santa Catarina. Peritos foram encontrados com registros de apenas três em Santa Catarina, enquanto auditores eram 153. Já, os contadores eram em número de 1.304 e auxiliar contábil, o CBO que mais teve presença no Estado, com o total de 4.991 profissionais registrados.

Mapa 1 - Centralização de auditores atuantes em Santa Catarina, $1^{\circ}$. semestre de 2018

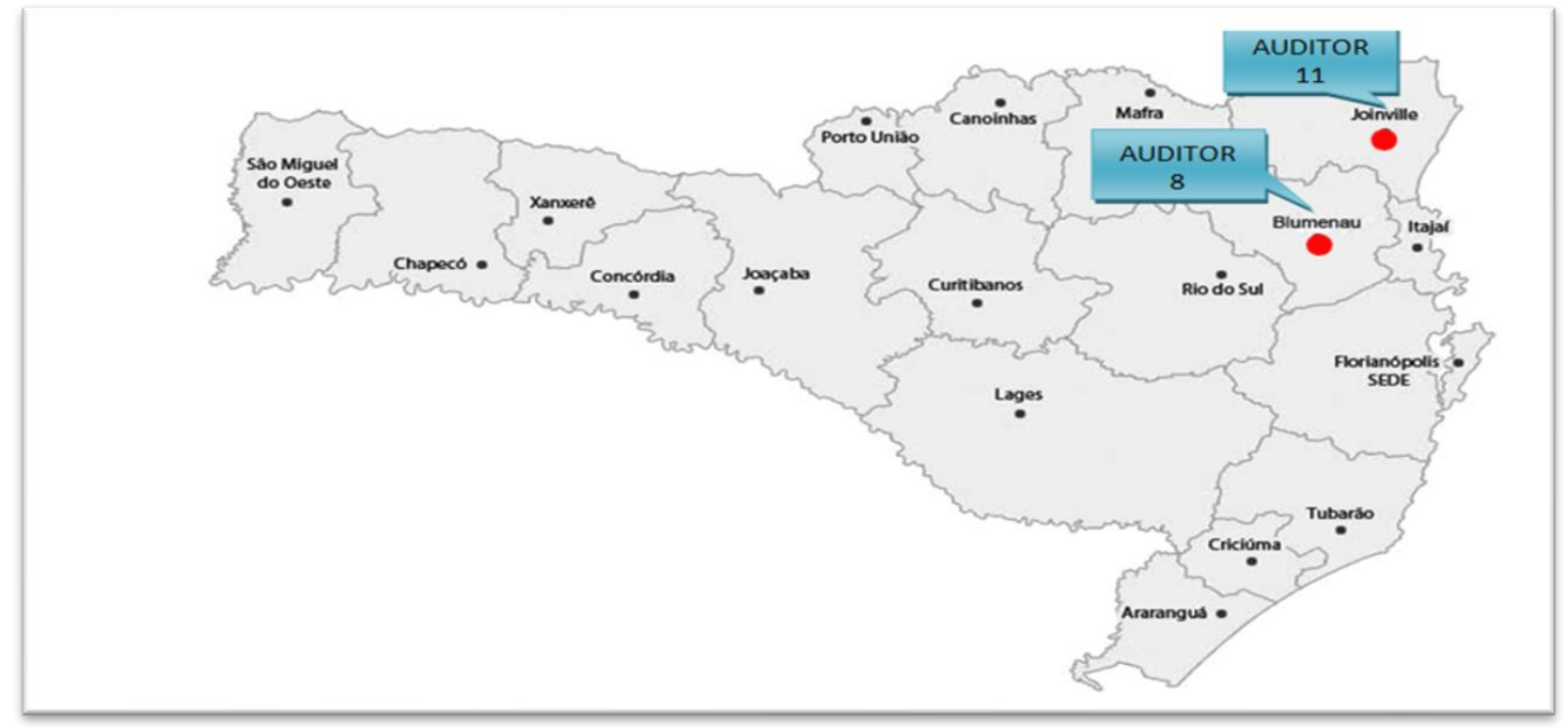

Fonte: Fonte: Elaborado a partir do CAGED - BRASIL, MTE (2018).

Com os dados do primeiro semestre de 2018 para Santa Catarina, observa-se que os auditores se concentraram na região Norte e Vale do Itajaí. Conforme o Conselho Regional 
de Contabilidade do Ceará (CRC/CE, 2018), a auditoria surgiu como consequência da necessidade de confirmação dos registros contábeis, em virtude do aparecimento das grandes empresas, baseado no lucro expresso nas demonstrações contábeis. Sua evolução ocorreu em paralelo ao desenvolvimento econômico e com as grandes empresas formadas por capital de muitas pessoas.

Segundo dados da Secretaria do Planejamento, em 2015, os cincos municípios que tiveram maior participação no PIB do Estado, foram Joinville, Itajaí, Florianópolis, Blumenau e São José, representando $37 \%$ da economia catarinense. Os dez maiores municípios de Santa Catarina representaram aproximadamente 50\% da economia no Estado. Desses municípios, destacaram-se, com maior crescimento em relação ao ano de 2014, São José, Florianópolis, Criciúma e Palhoça, motivados pelo setor de serviços.

Os dados apontaram presença elevada de contadores em Santa Catarina, com ênfase para as regiões de Joinville e Blumenau, regiões em que se encontram localizadas as maiores empresas. O PIB catarinense somou R $\$ 129,8$ bilhões, representando 4\% da economia do país. Apesar do ano sofrível, Santa Catarina manteve a sua importância no cenário nacional e permaneceu com o quarto maior PIB per capita, subindo de $\mathrm{R} \$ 20.369$ para $\mathrm{R} \$ 22.103$, valor $30 \%$ superior à média do país. (SINDIFISCO, 2018).

Mapa 2 - Centralização de contadores atuantes em Santa Catarina, $1^{\circ}$. semestre de 2018

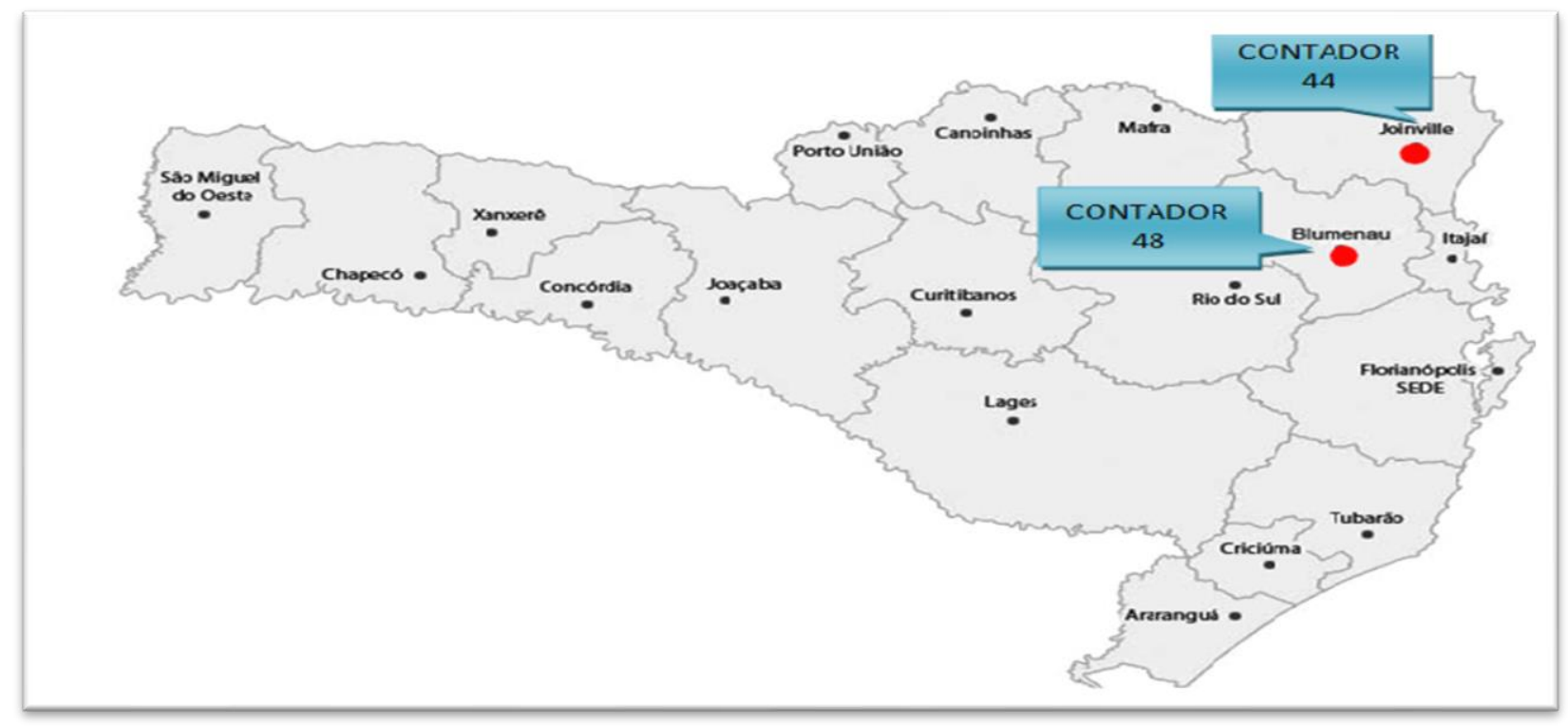

Fonte: Fonte: Elaborado a partir do CAGED - BRASIL, MTE (2018).

O Conselho Federal de Contabilidade (CFE, 2017) indicou que o país tem 349.171 contadores ativos nos Conselhos Regionais de Contabilidade. Além disso, apontou que o 
Brasil tem 61.864 organizações contábeis, divididas entre Sociedades (35.039), Empresários (13.264), Micro Empreendedores Individuais - MEI (8.857) e Empresas Individuais de Responsabilidades Limitada - Eireli (4.704). O registro apontou que a maioria dos profissionais ativos no CFC era do sexo masculino, 188.260 homens, um pouco a mais do que as 160.911 mulheres que atuam na profissão.

Conforme os indicadores econômicos estaduais, o maior número de auxiliares contábeis estava alocado nas cidades e regiões com algumas das empresas mais representativas da economia do Estado. Conforme microdados do CAGED, a média de empresas encontradas na região de Joinville estavam nas seguintes atividades: 44\% Serviços; 28\% Indústria; 22\% Comércio e 6\% de Construção Civil. Vale salientar que Joinville constitui a maior e mais populosa cidade do Estado.

Em Florianópolis encontra-se uma economia pautada em $66 \%$ de Serviços; $25 \%$ Comércio; $5 \%$ Construção Civil e 4\% na Indústria. É a segunda cidade mais populosa do Estado e ressalta-se que a economia de Florianópolis se encontra fortemente baseada na tecnologia da informação, no turismo e nos serviços.

Por fim, Blumenau possui uma economia assim distribuída: 36\% Industrial 35\% de Serviços; $23 \%$ Comércio e $6 \%$ da Construção Civil. Constitui a terceira cidade mais populosa do Estado, com a economia forte no setor têxtil, informática e também serviços e comércio.

Mapa 3 - Centralização de auxiliar contábil atuantes em Santa Catarina, $1^{\circ}$. semestre de 2018

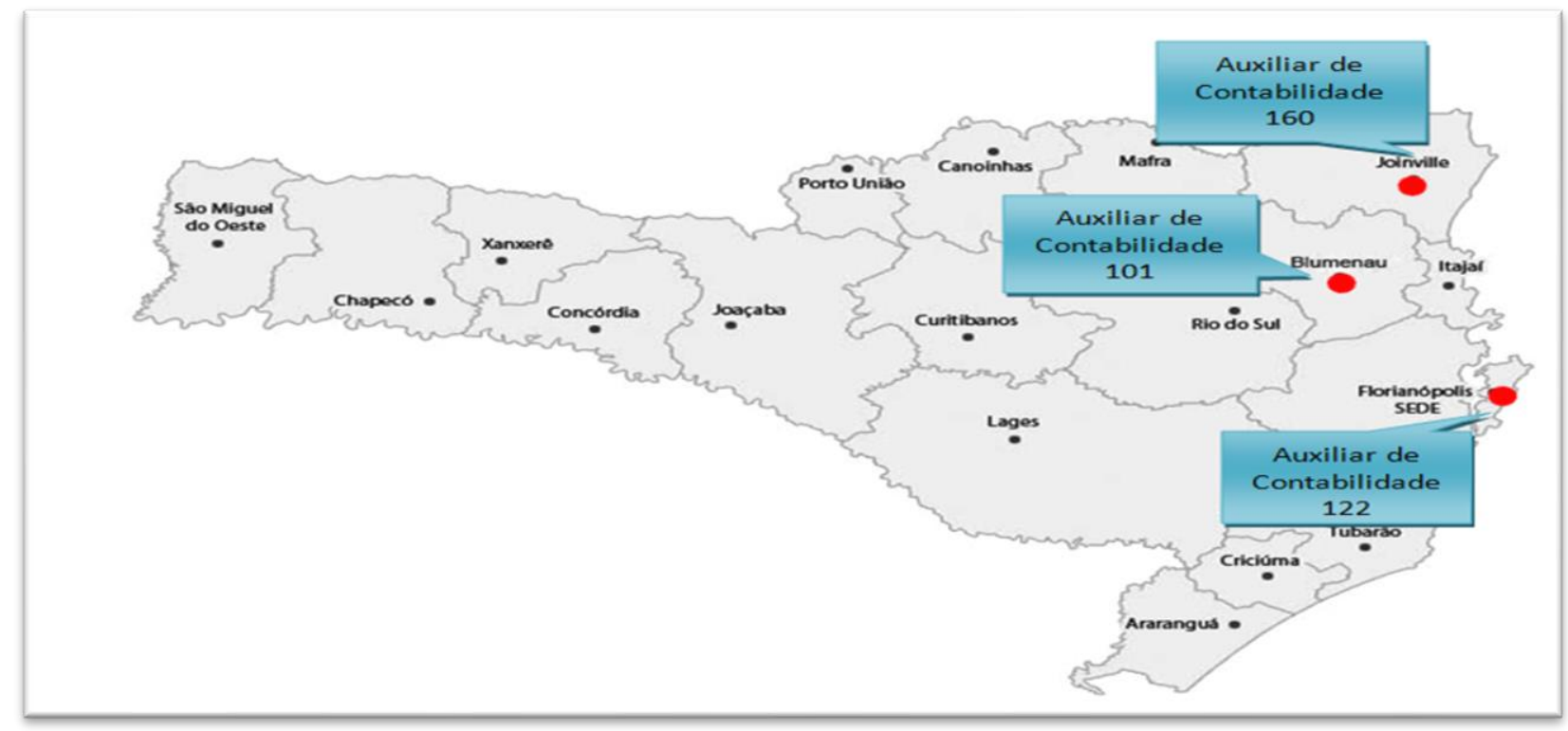

Fonte: Fonte: Elaborado a partir do CAGED - BRASIL, MTE (2018). 
Com o pequeno índice de Peritos registrado no Estado de Santa Catarina, nota-se que conforme gráfico anterior, sua distribuição. Nessa encontra-se Chapecó, um município muito forte na indústria e educação. Conforme dados apresentava no primeiro semestre de 2018: 36\% Serviços; 25\% Indústria; 28\% Comércio e 11\% Construção Civil. Tubarão tem $44 \%$ de Serviços; 27\% Comércio; 23\% Indústria e 6\% Construção Civil.

Mapa 4 - Centralização de peritos atuantes em Santa Catarina, $1^{\circ}$. semestre de 2018

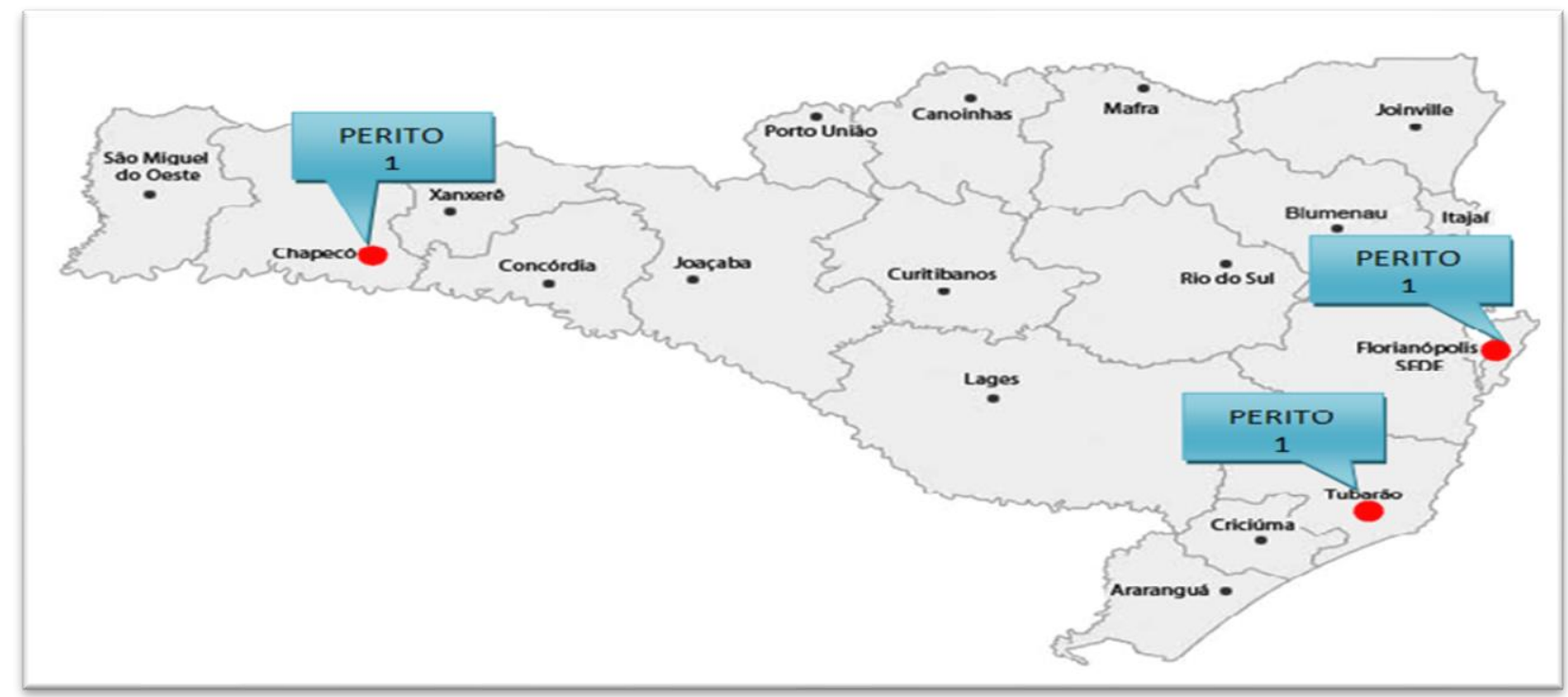

Fonte: Fonte: Elaborado a partir do CAGED - BRASIL, MTE (2018).

Conforme Spellmeier (2018), o perito-contador é requisitado quando alguém (pessoa física ou jurídica) pretende rever alguma relação ou contrato estabelecido, tanto na espera extrajudicial quanto no processo judicial. Quando há provas apresentadas ou a serem produzidas que se necessita de um especialista em matéria contábil.

\section{Considerações finais}

Pode-se notar através do estudo que as profissões de Perito e Auditor não têm muita presença em Santa Catarina. Santa Catarina é um Estado com forte presença de pequenas e médias empresas, no qual, não há tanta necessidade de Perícia Contábil e Auditoria. Contudo, podemos analisar a presença de muitos auxiliares de contabilidade centralizados em determinadas regiões, onde se encontram as maiores quantidades de empresas em Santa Catarina. 
Dado o exposto, nota-se também que o setor contábil mantém a média de contratações e demissões, concluindo que a demanda de serviço contábil não decaiu apesar do momento de crise econômica no país. Por outro lado, registrou grande rotatividade de pessoal, o que pode ocorrer por diversos fatores, sendo eles por competitividade empresarial, descontentamento com o trabalho ou até mesmo questões salariais.

Tendo em vista os aspectos observados com relação à desigualdade de gênero, percebeu-se que a mulher contabilista tem vasto espaço no mercado contábil. Qualificandose em maior percentual que os homens, as mulheres podem logo ultrapassar a taxa de homens registrados no setor contábil em Santa Catarina e obterem maior empoderamento no ramo.

Contendo maiores índices de contratações e demissões, conforme o estudo feito, a mulher tem se dedicado mais aos estudos que os homens, fator importante na hora da contratação de um profissional qualificado. Apesar disso, o estudo foi direcionado apenas ao turnover, não tendo pesquisado com maior profundidade os fatores relacionados às diferenças salariais.

Por todos esses aspectos, pode-se concluir que o ramo contábil é primordial até mesmo em tempos de crise, se não, necessário ainda mais nesse período, pois, a contabilidade é uma ferramenta de grande valia ao gestor para tomada de decisões e/ou novas estratégias de sua entidade em meio ao mundo globalizado.

Nestes termos, o estudo atingiu seu objetivo de analisar como o setor contábil se encontra no momento atual econômico. Considerou a mulher está inserida cada vez mais nesse setor, e fica a sugestão para um estudo mais aprofundado acerca das diferenças salariais entre homens e mulher contabilistas.

\section{REFERÊNCIAS}

ALMEIDA, C. B. A.; DE MESQUITA FERREIRA, L. C. Rotatividade de funcionários e desempenho organizacional: um estudo no comércio brasileiro. Brazilian Business Review (Portuguese Edition), jul. 2015. v. 12, n. 4, p. 28-61. Disponível em: http://search.ebscohost.com/login.aspx?direct=true\&db=foh\&AN=108416059\&lang=ptbr\&site=ehost-live. Acesso em: 31 out. 2018.

BRASIL. MINISTÉRIO DO TRABALHO E EMPREGO - MTE. CAGED - Cadastro Geral de Empregados e Desempregados. 2018. Disponível em: http://pdet.mte.gov.br/acessoonline-as-bases-de-dados. Acesso em: 10 set. 2018.

BRIGHENTI, J.; JACOMOSSI, F.; DA SILVA, M. Z. Desigualdades de gênero na atuação de Contadores e auditores no mercado de trabalho Catarinense. Enfoque: Reflexão 
Contábil, maio. 2015. v. 34, n. 2, p. 109-122. Disponível em: http://search.ebscohost.com/login.aspx?direct=true \&db=foh\&AN=116260169\&lang=ptbr\&site=ehost-live. Acesso em: 31 out. 2018.

CLOSER, C. A atuação da mulher contabilista nas organizações contábeis de florianópolis.2005. Disponível em: http://tcc.bu.ufsc.br/Contabeis294519.PDF. Acesso em: 01 nov. 2018.

CFC - CONSELHO FEDERAL DE CONTABILIDADE. Retomada da economia reforça importância do contador. 2017. Disponível em: https://cfc.org.br/noticias/retomada-daeconomia-reforca-importancia-do-contador/. Acesso em: 02 nov. 2018.

CFC - CONSELHO FEDERAL DE CONTABILIDADE. População brasileira versus contabilistas. 2010. Disponível em: http://www1.cfc.org.br. Acesso em: 23 out. 2018.

CFC - CONSELHO FEDERAL DE CONTABILIDADE. Retomada da economia reforça importância do contador. 2017. Disponível em: https://cfc.org.br/noticias/retomada-daeconomia-reforca-importancia-do-contador/. Acesso em: 02 nov. 2018.

CRC/CE - CONSELHO REGIONAL DE CONTABILIDADE DO ESTADO DE CEARÁ. Auditoria contábil: origem da auditoria contábil. Disponível em: http://www.crcce.org.br/fiscalizacao/informacoes-importantes/auditoria-contabil/. Acesso em: 02 nov. 2018.

FERREIRA, L. C. M.; ALMEIDA, Ciro B. Rotatividade de funcionários e desempenho organizacional: um estudo no comércio brasileiro. 2014. 28 - 61 p. Dissertação (Mestrado em Administração) - Faculdade de Ciências Econômicas, Insper, [S.1.], 2015.

IBGE - INSTITUTO BRASILEIRO DE GEOGRAFIA E ESTATÍSTICA Portal do. Estatística por cidade e estado. 2018. Disponível em: https://www.ibge.gov.br/estatisticasnovoportal/por-cidade-estado-estatisticas.html. Acesso em: 18 out. 2018.

MACHADO, C. R.; GRANEMANN, C. M. Empoderamento da mulher contadora: disparidades nas contratações. In: Trend Cont: produção científica em ciências contábeis [recurso eletrônico] Universidade do Contestado; organização Debora Aparecida Almeida ... [et al.]. Curitibanos, SC: Universidade do Contestado, 2017. 147 f. p. 57-68.

MARION, J. C. A disciplina teoria da contabilidade nos cursos de graduação: algumas considerações. Contabilidade Vista e Revista, Belo Horizonte, v. 8, n. 2, p. 3-8, 1997.

NASCIMENTO, S. S. As mulheres em Sergipe. 2014. Disponível em: http://www.jornaldodiase.com.br/noticias_ler.php?id=13587. Acesso em: 31 out. 2018.

NASCIMENTO, V. M. S.; ALVES, F. J. S. Gênero e carreira: um estudo de caso das percepções de contadores públicos. In: XIV Congresso USP Controladoria e Contabilidade, 14, 2014, São Paulo. Novas Perspectivas na Pesquisa Contábil. São Paulo: Anais, 2014. v. $1, \quad$ p. $\quad 1 \quad-\quad 10 . \quad$ Disponível em: https://congressousp.fipecafi.org/anais/artigos142014/380.pdf. Acesso em: 01 nov. 2018. 
OLIVEIRA, K. B.; LOPES, G. S. C.; WATANABE, M.; YAMAGUCHI, C. K.; DUARTE, R. Estudo do empoderamento na perspectiva de mulheres líderes. Revista Pretexto, Belo Horizonte v. 16, n. 4 p. 82-99, out/dez, 2015. Disponível em: http://search.ebscohost.com/login.aspx?direct=true \&db=foh\&AN=112188324\&lang=ptbr\&site=ehost-live. Acesso em: 31 out. 2018.

OLIVEIRA, L. B.; DA COSTA ROCHA, J. Engajamento no trabalho: antecedentes individuais e situacionais e sua relação com a intenção de rotatividade. Revista Brasileira de Gestão de Negócios, jul. 2017. v. 19, n. 65, p. 415-431. Disponível em: http://search.ebscohost.com/login.aspx?direct=true \&db=foh\&AN=124444950\&lang=ptbr\&site=ehost-live. Acesso em: 31 out. 2018.

PASETTO, N. A. A representatividade feminina na contabilidade. 2018. Disponível em: https://cfc.org.br/sem-categoria/a-representatividade-feminina-na-contabilidade/. Acesso em: 01 nov. 2018.

PINHEIRO, A. P; SOUZA, D. A. Causas e efeitos da rotatividade de pessoal turnover: estudo de caso de uma microempresa do setor de educação. Simpósio da excelência em gestão e tecnologia. 2013. Disponível em: http://www.aedb.br. Acesso em: 02 nov. 2018.

SANTA CATATINA. SECRETARIA DO PLANEJAMENTO DO GOVERNO DE SANTA CATARINA. PIB dos municípios catarinenses. 2017. Disponível em: http://www.spg.sc.gov.br/noticias/1864-secretaria-do-planejamento-divulga-resultados-dopib-dos-municipios-catarinenses. Acesso em: 29 out. 2018.

SANTOS, F. O empoderamento das mulheres na contabilidade. 2018. Disponível em: https://cfc.org.br/noticias/o-empoderamento-das-mulheres-na-contabilidade/. Acesso em: 01 nov. 2018.

RODRIGUES, P. A.; P.; FILHO, A. P.; SIQUEIRA, M. M. Bem-estar no trabalho e percepção de sucesso na carreira como antecedentes de intenção de rotatividade. Revista de Administração Mackenzie, nov. 2015. v. 16, n. 6, p. 71-93. Disponível em: http://search.ebscohost.com/login.aspx?direct=true \&db=foh\&AN=112385373\&lang=ptbr\&site=ehost-live. Acesso em: 31 out. 2018.

SEBRAE - SERVIÇO BRASILEIRO DE APOIO ÀS MICRO E PEQUENA EMPRESAS. Saiba o que é turnover e entenda o impacto da rotatividade no negócio. $2016 . \quad$ Disponível em: http://www.sebrae.com.br/sites/PortalSebrae/artigos/entenda-o-que-e-turnover-e-oimpacto-da-rotatividade-no-negocio,44e08fa0672f0510VgnVCM1000004c00210aRCRD. Acesso em: 22 out. 2018.

SINDIFISCO - SINDICATO DOS FISCAIS DO ESTADO DE SANTA CATARINA. PIB de Santa Catarina cai duas posições no ranking nacional. 2018. Disponível em: http://www.sindifisco.org.br/noticias/pib-de-santa-catarina-cai-duas-posicoes-no-rankingnacional. Acesso em: 29 out. 2018.

SPELLMEIER, R. L. Mercado oferece boas oportunidades para os peritos contábeis. 2018. Disponível em: http://www.crcsc.org.br/comunicacao/noticias/558- 
060711-mercado-oferece-boas-oportunidades-para-os-peritos-contabeis. Acesso em: 02 nov. 2018. 